\title{
Gastrointestinal Parasitic Infection in Captive Herbivores of Kanan Pendari Zoo, Bilaspur, Chhattisgarh
}

\author{
J. K. Khutey ${ }^{1}$, S. Chandrakar ${ }^{1}$, S. Roy ${ }^{1}$, J. Singh ${ }^{1} *$, S. L. Ali ${ }^{2}$, M. Roy ${ }^{3}$, \\ Smita $^{4}$, N. Jangde ${ }^{5}$, R. S. Kashyap ${ }^{2}$ and B. Mishra ${ }^{1}$ \\ ${ }^{1}$ Department of Wildlife Health and Forensic Centre, \\ ${ }^{2}$ Department of Veterinary Medicine, \\ ${ }^{3}$ Department of Veterinary Biochemistry, \\ ${ }^{4}$ Department of Veterinary Public Health, College of Veterinary Science and A.H., DSVCKV, \\ Durg-491001, Chhattisgarh, India \\ ${ }^{5}$ Department of Animal Breeding and Genetics, National Dairy Research Institute, Karnal, \\ Haryana, India \\ *Corresponding author
}

\section{A B S T R A C T}

Keywords

Captive wild herbivores, gastrointestinal parasites, Zoo

Article Info

\section{Accepted:} 12 April 2021 Available Online: 10 May 2021
The present study was undertaken to study the prevalence of gastro-intestinal parasites (GIP) in captive wild herbivores housed in Kanan Pendari Zoo (KPZ), Bilaspur, Chhattsigarh. A total of 226 faecal samples were examined by direct, sedimentation, floatation method and Mc master technique. The overall prevalence of gastro-intestinal parasites in captive wild herbivores was reported to be $28.31 \%$. Seasonal prevalence was reported to be $26.00 \%$ in summer season and $30.15 \%$ in pre-monsoon season. Amongst all species of captive wild herbivores studied, Blue bull showed highest prevalence $(75.00 \%)$ of GI parasites. During the study, prevalence of trematodes was $42.18 \%$, nematodes was $51.56 \%$ and mixed infection was recorded in $6.25 \%$ cases. Paramphistomum spp. was the most commonly observed GIP in $42.18 \%$ (26/64) animals while Strongyloides was least reported species in $10.90 \%$ (7/64) animals. The highest Egg per gram (EPG) count was observed in Black buck during pre-monsoon season $(\mathrm{EPG}=800)$ and lowest EPG (100) count was recorded in Hog deer and blue bull during pre-monsoon season.

\section{Introduction}

Parasitic diseases play an important role in healthcare and management of wild animals in captivity. The health status of captive animal depends on many factors like feeding, keeping conditions, animal management and environmental conditions such as temperature, rainfall and humidity (Goossens et al., 2005). Various species of captive wild animals have 
been found to be infested by different types of endoparasites leading to variable degree of morbidity and mortality (Singh et al., 2009).

In captivity, wild animals may succumb to parasitic infection due to environmental stress such as change in living conditions and space limitations (Atanaskova et al., 2011). Despite of various studies carried out on parasitic diseases in wildlife (Islam, 2006), there is still scarcity in terms of documented reports of prevalence of gastrointestinal parasites in captive wild herbivores of Chhattisgarh.

\section{Materials and Methods}

\section{Study area}

The present study was carried out to study the prevalence of parasitic infection in wild herbivore animals kept at Kanan Pendari Zoo, Bilaspur, Chhattisgarh.

Kanan Pendari Zoo, Bilaspur is located between $22^{\circ} 05^{\prime} \mathrm{N}, 82^{\circ} 13^{\prime} \mathrm{E}$ at Bilaspur city and is spread across an area of 114 hectares. The study programme was carried out over a period of 05 months from March, 2018 to July, 2018 in two different seasons viz. summer (March to May) and pre-monsoon (June to July).

\section{Collection of faecal samples}

Freshly passed faecal samples were collected from the animal enclosure in clean, dry interlocked polythene bags as described by Chandrakar et al., (2020). The samples were labeled indicating animal information viz. species, age, sex and enclosure number respectively for easy identification of the samples for laboratory analysis

\section{Sedimentation method}

About one gram of faeces was taken in pestle and mortar followed by addition of little amount of distilled water and mixed properly. The suspension was strained to remove any debris followed by centrifugation for 2 to 3 minutes@1500rpm.

The supernatant was discarded and a drop of sediment was placed on clean grease free glass slide and was covered with a clean cover slip avoiding any air bubble. The slide was examined under low power objective (10X) of microscope (Soulsby, 1982).

\section{Floatation method}

About one gram of faeces was taken in pestle and mortar and adequate amount of saturated solution of magnesium sulphate was added and mixed thoroughly.

The suspension was strained to remove any debris and centrifuged @ 1500 rpm for 2 to 3 minutes. The surface layer was examined under low power objective (10X) of microscope for the presence of parasitic eggs (Soulsby, 1982).

\section{Mc master method for EPG}

The method suggested by Skerman and Hillard (1966) was used for estimation of EPG of faeces. About $2 \mathrm{gm}$ of faecal sample was added to $20 \mathrm{ml}$ of water in a beaker. It was left for 30 minutes for soaking.

Afterwards, the whole sample was taken into the pestle and mortar and was mixed thoroughly. The sample was again poured back into the same beaker and about $40 \mathrm{ml}$ of saturated salt solution was added. Then mixing was done thoroughly without forming air bubbles (Dilution factor is 1 in 30).

One ruled chamber of the Modified McMaster Slide was charged and all eggs were counted under low power (10X) of the microscope. The value of EPG was determined by formula as number of eggs counted $\mathrm{x} 100$. 


\section{Results and Discussion}

\section{Overall prevalence}

The overall prevalence of gastro-intestinal parasites in captive herbivores at Kanan Pendari Zoo, Bilaspur was $28.31 \%$ (64/226) which is presented in table no. 1 and fig. 1.

The findings of our study are in concordance with prevalence rate of gastro-intestinal parasites (33.33\%) in Assam State Zoo, Guwahati (Borodoloi et al., 1991). Similarly, prevalence rate of $35.60 \%$ has been reported in Rangpur Recreational Garden and Zoo, Bangladesh (Khatun et al., 2014).

However, the prevalence recorded in our study was comparatively lower than the findings of Thawait et al., (2014) who have reported prevalence of $46.20 \%$ in animals of Nandan Van Zoo, Raipur, Chhattisgarh. Varadharajan et al., (2001) have also reported a higher prevalence rate of gastro-intestinal parasites (68.05\%) in captive wild animals of Thrissur Zoo Kerala. Similarly, a much higher prevalence rate of $68.0 \%$ has been reported by Mir et al., (2016) in their work carried out in Bir Moti Bagh Mini Zoo (Deer Park), Patiala, Punjab.

\section{Seasonal prevalence}

The season wise prevalence of gastrointestinal parasites in captive wild herbivores has been represented in table no. 2 and fig. 2 .

Out of 226 fecal samples examined during the study period, 100 samples were collected in summer (March-May) season while 126 samples were collected in pre-monsoon (JuneJuly) season. The findings of faecal sample examination revealed that 26 samples were found to be infected with gastro-intestinal parasites in summer season while 38 samples were found to be infected in pre-monsoon season, thereby indicating prevalence of $26.00 \%(26 / 100)$ in summer and $30.15 \%$ (38/126) pre-monsoon season respectively.

The findings of our study are in concordance with prevalence rate of gastro-intestinal parasites in summer $(26.00 \%)$ and rainy season $(30.15 \%)$ in Van Vihar National Park, Bhopal (Singh et al., 2009).

Similarly, prevalence rate of $27.5 \%$ in summer and $40.5 \%$ in rainy season has been reported in animals of Balodyan and Maharajabag Zoo, Nagpur (Jadhav et al., 2010).

However, the season wise prevalence was observed to be comparatively lower than the findings of Sahoo et al., (2009) who have reported prevalence of $47.62 \%$ in captive wild animals of Nandankanan Zoological Park, Bhubaneswar, Orissa. Barmon et al., (2014) have also reported a higher prevalence rate of gastro-intestinal parasites in summer (70.59\%) and winter $(66.67 \%)$ in wild animals of Char Kukri Mukri Upzilla of Bhola district of Bangladesh.

\section{Species wise prevalence}

The prevalence of gastro-intestinal parasites in different species of captive wild herbivores has been represented in table no. 3 and fig. 3 .

Among different herbivores, Blue bull showed highest prevalence $(75.00 \%)$ of GI parasites followed by hog deer $(50.00 \%)$, barasingha $(43.75 \%)$, barking deer $(33.33 \%)$, spotted deer (28.00\%), black buck (26.31\%), sambar $(20.00 \%)$ and chausingha (10.34\%) respectively.

The findings of our study are in concordance with prevalence rate of gastro-intestinal parasites of Spotted deer (28.57\%) in Pench National Park, Maharashtra (Nighot et al., 2004). 
Table.1 Overall prevalence (\%) of GIP in captive wild herbivores in KPZ, Bilaspur

\begin{tabular}{|c|c|c|}
\hline $\begin{array}{c}\text { Total no. of faecal samples } \\
\text { examined }\end{array}$ & $\begin{array}{c}\text { No. of positive faecal } \\
\text { samples }\end{array}$ & $\begin{array}{c}\text { Prevalence } \\
(\boldsymbol{\%})\end{array}$ \\
\hline $\mathbf{2 2 6}$ & 64 & 28.31 \\
\hline
\end{tabular}

Table.2 Season wise prevalence (\%) of GIP in captive wild herbivores in KPZ, Bilaspur

\begin{tabular}{|c|c|c|c|}
\hline Season & $\begin{array}{c}\text { No. of faecal samples } \\
\text { examined }\end{array}$ & $\begin{array}{c}\text { No. of positive faecal } \\
\text { samples }\end{array}$ & $\begin{array}{c}\text { Prevalence } \\
(\mathbf{\%})\end{array}$ \\
\hline Summer & 100 & 26 & 26.00 \\
\hline Pre-monsoon & 126 & 38 & 30.15 \\
\hline
\end{tabular}

Table.3 Species wise prevalence (\%) of GIP in captive wild herbivores in KPZ, Bilaspur

\begin{tabular}{|c|c|c|c|}
\hline Species & $\begin{array}{c}\text { No. of faecal } \\
\text { samples examined }\end{array}$ & $\begin{array}{c}\text { No. of positive faecal } \\
\text { samples }\end{array}$ & $\begin{array}{c}\text { Prevalence } \\
\text { (\%) }\end{array}$ \\
\hline $\begin{array}{c}\text { Blue bull } \\
\text { (Boselaphus tragocamelus) }\end{array}$ & 16 & 12 & 75.00 \\
\hline $\begin{array}{c}\text { Hog deer } \\
\text { (Axis porcinus) }\end{array}$ & 4 & 2 & 50.00 \\
\hline $\begin{array}{c}\text { Barasingha } \\
\text { (Rucervus duvaucelii) }\end{array}$ & 16 & 7 & 43.75 \\
\hline $\begin{array}{c}\text { Barking deer } \\
\text { (Muntiacus muntjak) }\end{array}$ & 6 & 2 & 33.33 \\
\hline $\begin{array}{c}\text { Spotted deer } \\
\text { (Axis axis) }\end{array}$ & 92 & 26 & 28.26 \\
\hline $\begin{array}{c}\text { Black buck } \\
\text { (Antilope cervicapra) }\end{array}$ & 38 & 10 & 26.31 \\
\hline $\begin{array}{c}\text { Sambar } \\
\text { (Cervus unicolor) }\end{array}$ & 10 & 2 & 20.00 \\
\hline $\begin{array}{c}\text { Chousingha } \\
\text { (Tetracerus quadricornis) }\end{array}$ & 29 & 3 & 10.34 \\
\hline
\end{tabular}

Table.4 Over all prevalence of different GIP

\begin{tabular}{|c|c|c|}
\hline Type of infection & $\begin{array}{c}\text { No. of Positive } \\
\text { samples }\end{array}$ & $\begin{array}{c}\text { Prevalence } \\
(\mathbf{\%})\end{array}$ \\
\hline Nematode (single) & 33 & 51.56 \\
\hline Trematode (single) & 27 & 42.18 \\
\hline Mixed infection & 4 & 6.25 \\
\hline
\end{tabular}


Table.5 Species wise prevalence (\%) of different GIP

\begin{tabular}{|c|c|c|}
\hline Species of parasite & \multicolumn{2}{|c|}{ Total no. of positive samples (n=64) } \\
\cline { 2 - 3 } & No. of positive samples & Prevalence (\%) \\
\hline Paramphistomum spp. & 27 & 42.18 \\
\hline Strongyle spp. & 26 & 40.60 \\
\hline Strongyloides spp. & 7 & 10.90 \\
\hline Strongyle spp. and Strongyloides spp. & 2 & 3.12 \\
\hline Strongyle spp. and Oesophgostomum spp. & 2 & 3.12 \\
\hline
\end{tabular}

Fig.1 Overall prevalence (\%) of GIP in captive wild herbivores in KPZ, Bilaspur

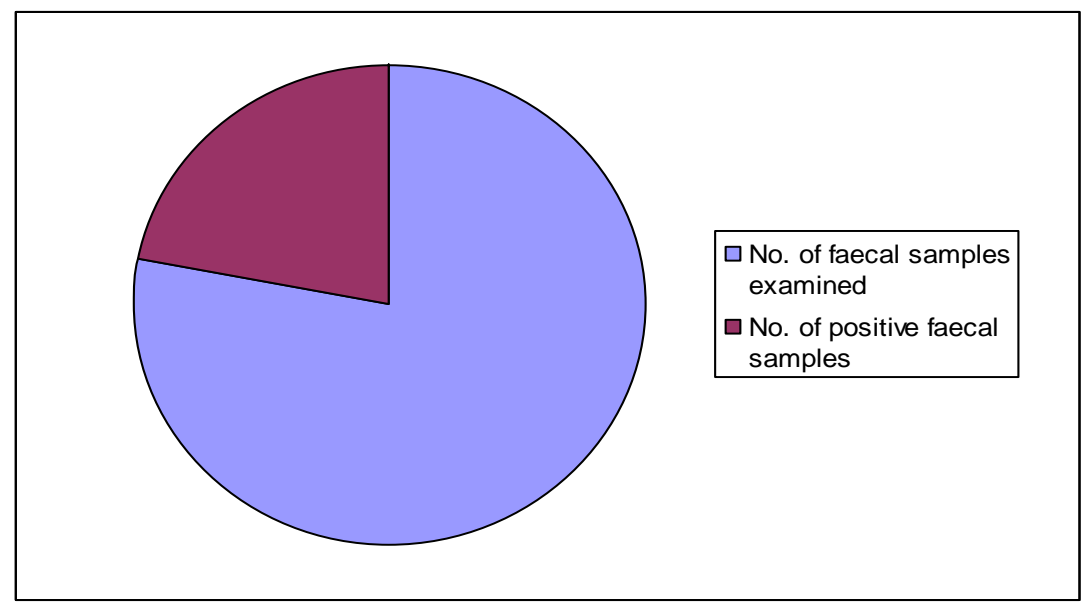

Fig.2 Season wise prevalence (\%) of GIP in captive wild herbivores in KPZ, Bilaspur

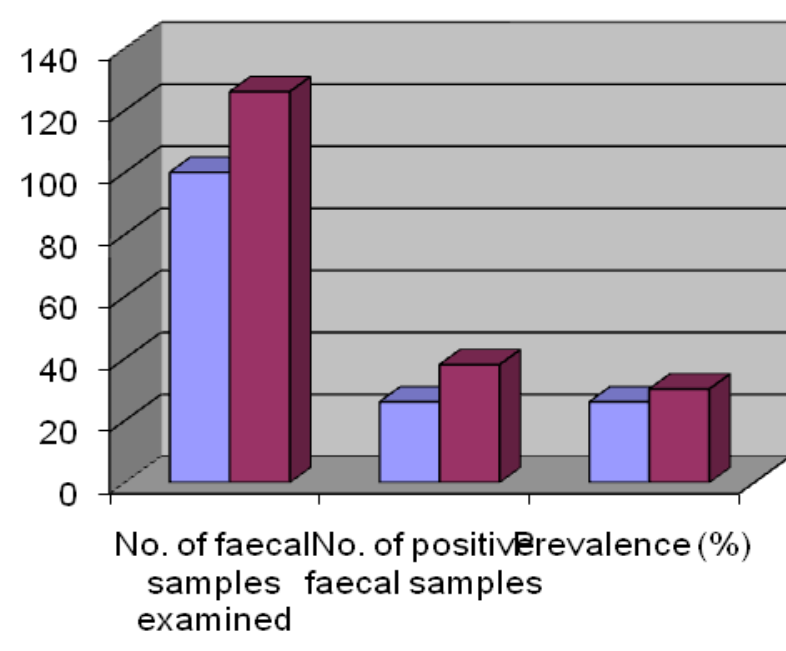


Fig.3 Species wise prevalence (\%) of GIP in captive wild herbivores in KPZ, Bilaspur

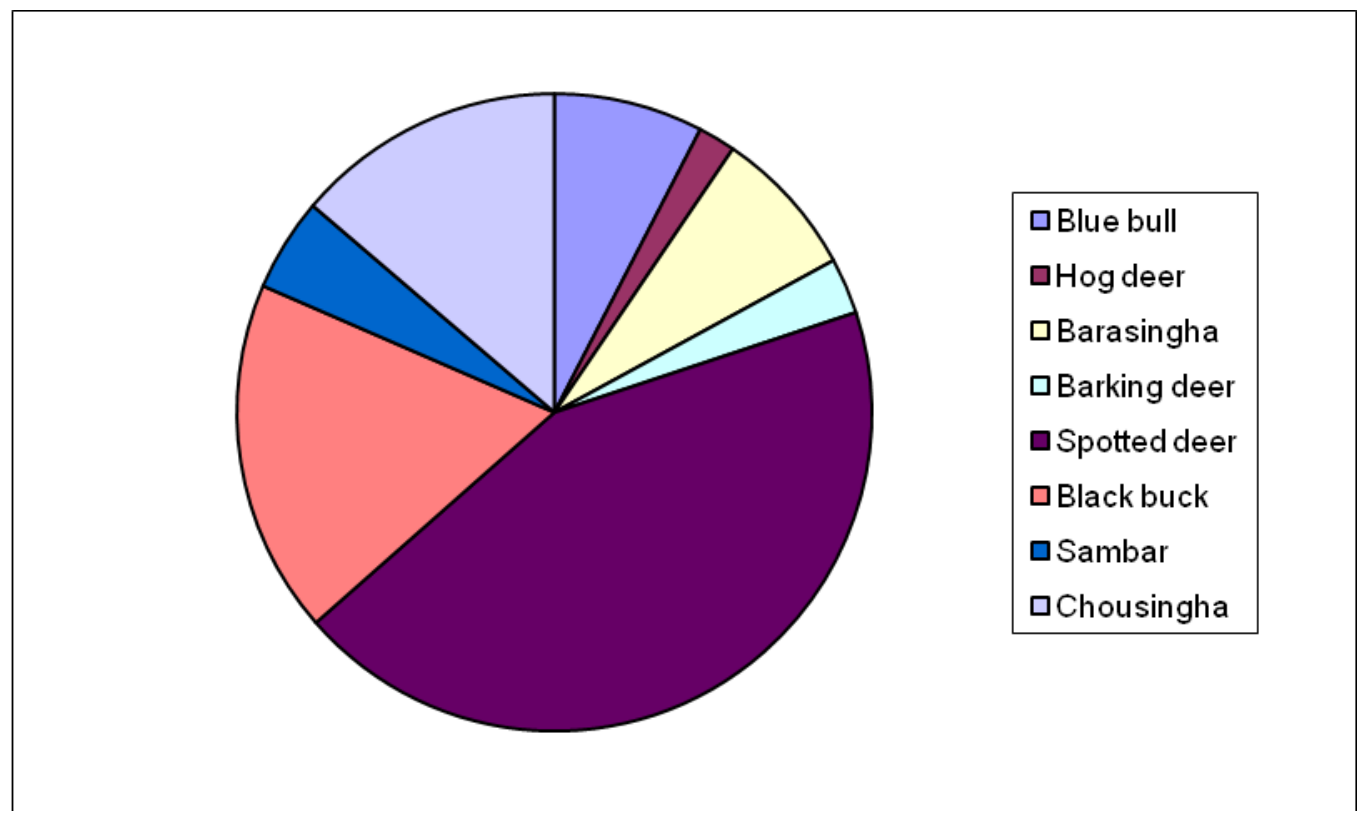

Fig.4 Over all prevalence of different GIP

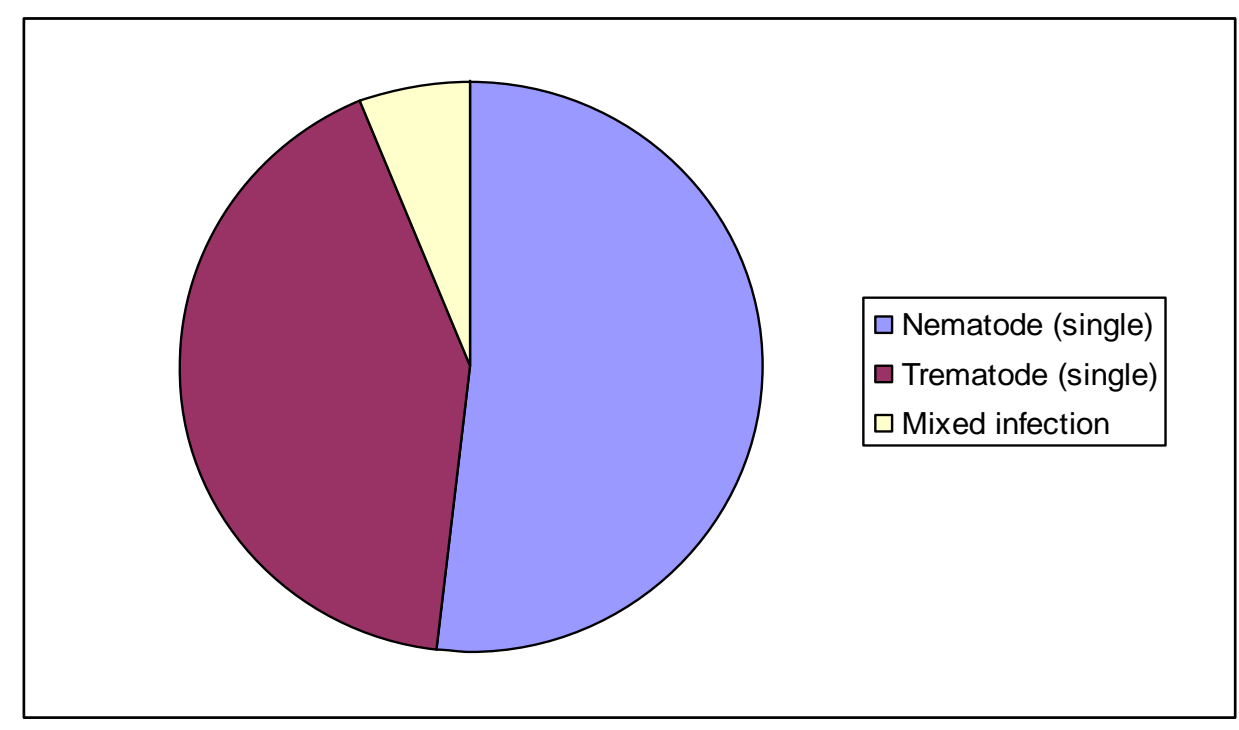


Fig.5 Species wise prevalence (\%) of different GIP

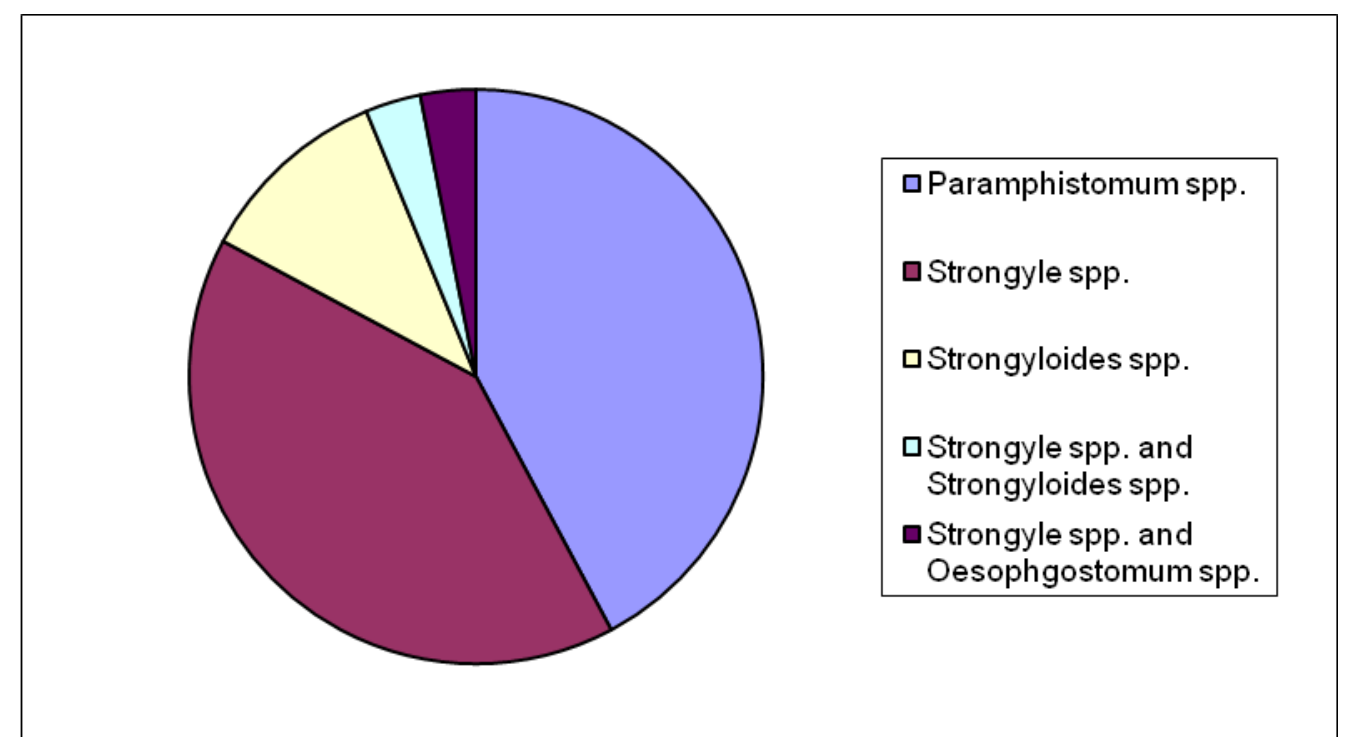

However, the species wise prevalence was observed to be comparatively lower than the findings of Mir et al., (2016) who have reported prevalence rate in barking deer (100\%), black buck (75.00\%), sambar (66.00\%), spotted deer $(50.00 \%)$ of Bir Moti Bagh Mini Zoo (Deer Park), Patiala, Punjab.

\section{Over all prevalence of different gastro- intestinal parasites}

The overall prevalence of different gastrointestinal parasites in captive wild herbivores has been represented in table no. 4 and fig. 4 .

The overall prevalence of nematode parasites was $51.56 \%$ (33/64) while trematode parasites were reported in $42.18 \%$ (27/64) wild herbivores during the study. However, mixed infection was detected in 04 samples indicating an overall prevalence of mixed infection to be $6.25 \%$ (04/64). The finding revealed that single nematode infection was significantly $(p \leq 0.05)$ higher than trematode and mixed infection in captive wild herbivores in our study. The prevalence of nematode infection in Kanan Pendari Zoo $(51.56 \%)$ is similar to the findings of Bante et al., (2013) who have reported $42.36 \%$ prevalence of nematodes in Kamala Nehru Prani Sangrahalaya, Indore.

\section{Species wise prevalence of different gastro- intestinal parasites}

The species wise prevalence of different gastro-intestinal parasites in captive wild herbivores in zoo has been represented in table no. 5 and fig. 5 .

Out of 64 positive samples from Kanan Pendari Zoo, Bilaspur, single infection with Paramphistomum spp. was recorded in 42.18\% (27/64) animals while Strongyle spp. was recorded in $40.60 \%(26 / 64)$ animals and Strongyloides spp. in $10.90 \%$ (7/64) animals respectively. Mixed parasitic infection of Strongyle spp. along with Oesophagostomum spp. was recorded in $3.12 \%(2 / 64)$ and Strongyle spp. with Strongyloides spp. was recorded in $3.12 \%(2 / 64)$ animals respectively.

Mandal et al., (2002) have reported infection of Strongyle spp. (41.7\%) followed by Paramphistomum spp. (15.6\%), Strongyloides spp. (11.5\%) respectively in wild animals of 
Mudumalai Wildlife Sanctuary, Tamilnadu. Singh et al., (2009) have reported highest prevalence for Strongyles (26.15\%) followed by Strongyloides spp. (7.13\%) and Paramphistomes (1.98\%) in captive wild animals of Van Vihar National Park, Bhopal. Rahman et al., (2014) have reported prevalence rate of Paramphistomum spp. (36.5\%), Strongyloides spp. (1.9\%) and Paramphistomum spp. (33.33\%) in captive wild animals of Dhaka National Zoological Garden, Bangladesh.

In contrast to our findings, Strongyle spp. was the most commonly observed GIP (62.50\%) while Paramphistomum was least reported species in $5.00 \%$ in captive wild herbivores of Nandanvan Zoo, Raipur (Khutey et al., 2020)

\section{Egg per gram count in different species}

The EPG count in Kanan Pendari Zoo, Bilaspur ranged from 100-800 among 02 different seasons. The highest EPG count was observed in Black buck during pre-monsoon season $(E P G=800)$. However, lowest EPG (100) count was recorded in Hog deer and Blue bull during pre-monsoon season.

Singh et al., (2009) have reported that overall mean EPG was maximum for Strongyles (585.19), followed by Amphistome (250) and Strongyloides (127.78) reported in captive wild animals of Van Vihar National Park, Bhopal.

Rahman et al., (2014) have reported an intensity of infection in terms of EPG ranging from 100-500 in Spotted deer of Dhaka National Zoological Garden, Bangladesh.

In another study, conducted in captive wild herbivores of Nandanvan Zoo, Raipur, highest EPG count was reported in Chausingha and blue bull during pre-monsoon season $(\mathrm{EPG}=$ 700) while lowest EPG (100) count was reported in Spotted deer during summer season (Khutey et al., 2020).

\section{Acknowledgement}

The authors are thankful to Chief Wildlife Warden, Govt. of Chhattisgarh, for kind permission for undertaking this research work. Authors are also thankful to Wildlife Veterinarian Kanan Pendari Zoo, Bilaspur and Dean, College of Veterinary Science and Animal Husbandry, Anjora, Durg for providing necessary samples and facilities to carry out this work.

\section{References}

Atanaskova, E., Kochevski, Z., Stefanovska, J. and Nikolovski, G. 2011. Endoparasites in wild animals at the Zoological garden in Skopje, Macedonia. Journal of Threatened Taxa, 3(7): 1955-1958.

Bante, S., Bagherwal, R. K. and Agrawal, V. 2013. Prevalence of helminth parasites in wild animals of Zoological Park at Indore. Indian Veterinary Journal, 90(7): 84-86.

Barmon, B. C., Begum, N., Labony, S. S., Kundu, U. K., Dey, A. R. and Dey, T. R. 2014. Study of gastrointestinal parasites of deer at Char Kukri Mukri in Bhola district. Bangladesh. Journal of Veterinary Medicine, 12: 27- 33.

Borodoloi, G. C., Dutta, G. C., Das, I., Pathak, M. and Choudhary, A. 1991. Note on incidence of intestinal helminthic infection of deer in captivity. Zoo's Print Journal, 6: 17.

Chandrakar, S., Khutey, J. K., Roy, S., Singh, J., Mishra, B., Jambagi, K., Markandey, D.,

Meshram, S., Ali, S. L. and Uppal, M. 2020. Prevalence of gastrointestinal nematodes in captive wild carnivores of Chhattisgarh, India. Internationa Journal of Current Microbiology and Applied Sciences, 9(3): 609-615.

Goossens, E., Dorny, P., Boomker, J., Vercammen, F. and Vercruysse, J. 2005. A 12-month survey of the gastro-intestinal helminthes of antelopes, gazelles and 
giraffids kept at two zoos in Belgium. Veterinary Parasitology, 127: 303-312.

Jadhav, P., Jadav, K., Chavan, P., Baviskar, B. and Maske, D.K. 2010. Seasonal variation in prevalence of helminthic infection in captive spotted Deer at Nagpur. Zoo's Print Magazine, 25 (5): 18-19.

Khatun, M. M., Begum, N., Mamun, M. A. I., Mondal, M. M. H. and Azam, M. S. U. 2014. Coprological study of gastrointestinal parasites of captive animals at Rangpur Recreational Garden and Zoo in Bangladesh. Journal of Threatened Taxa, 6(8): 6142-6147.

Khutey, J. K., Chandrakar, S., Roy, S., Singh, J., Mishra, B., Jambagi, K., Kashyap, R, Meshram, S., Ratre, H. K. and Ali, S.L. (2020). Studies on prevalence of gastrointestinal parasites in captive wild herbivores in Nandanvan Zoo, Raipur. Journal of Entomology and Zoology Studies, 8(2): 645-648.

Mandal, P., Jayathangaraj, M. G., John, L., Latha, B. R. and Raman, M. 2002. Prevalence of helminthic infection in free-ranging Chital (Axis axis) at Madumalai Wildlife Sanctuary, Tamil Nadu, Proceedings of the XIII ${ }^{\text {th }}$ National Congress of Veterinary Parasitology, $14^{\text {th }}$ to $16^{\text {th }}$ February, 2002, Kolkata.

Mir, A. Q., Dua, K., Singla, L. D., Sharma, S. and Singh, M. P. 2016. Prevalence of parasitic infection in captive wild animals in Bir Moti Bagh Mini Zoo (Deer Park), Patiala, Punjab. Veterinary World, 9(6): 540-543.

Nighot, N. K., Sarode, D. B., Dakshinkar, N. P., Kolte, S. W. and Bhojne, G. R. 2004. Prevalence of helminthes in wild and domestic animals of Pench National Park, Maharashtra. Paper presented at National symposium on Latest approach and biotechnological tools for health management of farm and companion animals held from 11-13 ${ }^{\text {th }}$ February, 2004. p.71.

Rahman, S. M., Dey, A. R., Kundu, U. K. and Begum, N. 2014. Investigation of gastrointestinal parasites of herbivores at Dhaka National Zoological Garden of Bangladesh. Journal of Bangladesh Agricultural University, 12(1): 79-85.

Sahoo, N., Roy, P. K., Das, A., Samantaray, R. K., Dehuri, M. and Bharti, K. M. N. 2009. Gastrointestinal helminthic infection in animals of Nandankanan Zoological Park. Journal Veterinary Parasitology, 23(1): 95-96.

Singh, S., Shrivastav, A. B. and Sharma, R. K. 2009. The epidemiology of gastrointestinal parasitism and body condition in herbivores in the Van Vihar National Park, Bhopal. Journal of Threatened Taxa, 1(10): 535- 537.

Skerman, K. D. and Hillard, J. J. 1966. A handbook for studies of helminth parasite of ruminant. Near East Animal Health Institute, Iran, FAO, Rome.

Soulsby, E. J. L. 1982. Helminths, Arthropods and Protozoa of domesticated animals. $7^{\text {th }}$ Edn. Blackwell Scientific Publications, London.

Thawait, V. K., Maiti, S. K. and Dixit, A. A. 2014. Prevalence of gastro-intestinal parasites in captive wild animals of Nandan Van Zoo, Raipur, Chhattisgarh. Veterinary World, 7(7): 448-451.

Varadharajan, A., Pythal, C. and Subramanian, H. 2001. Investigation on the prevalence of helminth parasites of wild mammals in the Thrissur zoo, Kerala. Cheiron 30: 12-15.

\section{How to cite this article:}

Khutey, J. K., S. Chandrakar, S. Roy, J. Singh, S. L. Ali, M. Roy, Smita, N. Jangde, R. S. Kashyap and Mishra, B. 2021. Gastrointestinal Parasitic Infection in Captive Herbivores of Kanan Pendari Zoo, Bilaspur, Chhattisgarh. Int.J.Curr.Microbiol.App.Sci. 10(05): 43-51. doi: https://doi.org/10.20546/ijcmas.2021.1005.008 